\title{
Do iberismo ao ibero-americanismo, da federação latina à confederação luso-brasileira - percursos e reflexões de alguns intelectuais portugueses entre os séculos XIX e XX
}

\author{
From Iberianism to Hispano-Americanism, from the Latin Federation to the Portuguese- \\ Brazilian Confederation - Paths and reflections of some Portuguese intellectuals \\ between the nineteenth and twentieth centuries
}

Maria Conceição Meireles

Doutora em História Professora da Universidade do Porto mcoelho@letras.up.pt

\begin{abstract}
Resumo: Este artigo pretende evidenciar o percurso de pensamento, muitas vezes complexo e até ambíguo, de alguns intelectuais portugueses de diferentes campos ideológicos, designadamente republicanos (principalmente federalistas) e integralistas monárquicos, entre meados do século XIX e inícios do século XX, relativamente às teorias iberistas e hispanoamericanistas que então foram formuladas, evidenciando a efetiva conexão entre elas e as suas similitudes e divergências considerando o quadro político antagónico, bem como o surgimento de outras formulações de entendimento supranacional (federação latina, união ocidental, panlusitanismo, hispanismo, aliança peninsular, confederação luso-brasileira) ora suscitadas por ideais pacifistas, ora emergindo em função do contexto específico da I Guerra Mundial.
\end{abstract}

Palavras-chave: Iberismo, Hispanoamericanismo, Confederação Lusobrasileira.
Abstract: This paper aims to highlight the often complex and even ambiguous thought path of some Portuguese intellectuals from different ideological fields, namely republicans (mainly federalists) and "integralist" monarchists, between the midnineteenth century and the early twentieth century, concerning theories of Iberianism and Hispano-Americanism, showing the effective connection between them and their similarities and divergences considering the opposite political frame, as well as the emergence of other formulations of supranational understanding (Latin federation, western union, pan-lusitanism, hispanism, peninsular alliance, PortugueseBrazilian confederation) raised by pacifist ideals or emerging in the specific context of World War I.

Keywords: Iberianism, HispanoAmericanism, Portuguese-Brazilian Confederation. 


\section{Introdução}

Por meados do século XIX, a questão ibérica ganhou em Portugal uma projeção inédita, decorrendo de duas tendências aparentemente contraditórias, mas ambas em voga na época: o utopismo das Luzes assente nas ideias de pacifismo e de fraternidade universal, e a valorização da especificidade nacional com o advento dos Estados-Nação e consequente movimento das nacionalidades. Desta forma, aspirava-se conjugar nacionalismo e ecumenismo, sendo evidente o "dilema em que se debatia o ideal ibérico: salvaguardar a identidade nacional sem bloquear a integração de Portugal nessa caminhada para a edificação da cosmopolis" (CATROGA, 1985: 423).

Num quadro imbricado de sistemas e valores, as proposições iberistas, que não conheceram concretização histórica, difundiram-se no imaginário coletivo, propulsionadas por teorias de intelectuais e políticos de diferentes craveiras, campo partidário ou quadrante ideológico, com uma forte repercussão na imprensa periódica. $\mathrm{O}$ terceiro quartel de Oitocentos constituiu um tempo forte da polémica, entre a publicação de obras que inflamaram a questão e o fim da interinidade espanhola, num crescendo da reação nacionalista portuguesa; mas, posteriormente, a crise do Ultimato inglês e a política de Afonso XIII, bem como o contexto internacional e a instauração da República em Portugal suscitaram vagas de idêntico teor polemista. Estas ideias não foram apanágio de republicanos progressistas, pois também monárquicos de diversas sensibilidades as defenderam, muitas vezes partilhando pressupostos, diferindo obviamente nos meios propostos. Foram numerosas as metamorfoses do ideal de entendimento peninsular, ao qual se associou a teorização de formas de aproximação da Península com a HispanoAmérica.

\section{Emergência das ideias ibéricas em Portugal}

Se, como explicou Sampaio Bruno, as origens da polémica remontavam ao emblemático ano de 1848 (BRUNO, [1906] 1987: 80), em plena “primavera dos povos”, quando 400 espanhóis e portugueses emigrados em Paris fundaram o Clube Democrático Ibérico e aclamaram a união peninsular (RIVAS, 1982: 320; MOLINER PRADA, 1989: 125), sendo então esse ideal tímida e clandestinamente advogado por folhas republicanas, ele foi claramente exposto em finais de 1851, por um realista espanhol, Sinibaldo de Mas, 
que advogou a união pacífica dos dois países sob a fórmula monárquica na obra A Ibéria, o mais lido dos catecismos ibéricos, amplamente difundido em três edições portuguesas e seis castelhanas, sucessivamente corrigidas e aumentadas, sempre profusamente ilustradas (PEREIRA, 2001) ${ }^{1}$. O tradutor português desta obra e autor do célebre prólogo foi Latino Coelho, que, todavia, só revelou a sua identidade na terceira edição; não obstante as suas simpatias republicanas, serviu a monarquia, designadamente como deputado, ministro e par do Reino. Patenteou nesse texto prefacial a sua crença na grande federação da Europa, geradora de paz e equilíbrio, ansiando pela "diminuição progressiva do número dos estados independentes". Cada fusão racional e espontânea entre povos com afinidades representava o apaziguamento e reconciliação entre eles, o desarmamento de dois exércitos, um novo triunfo da humanidade, enfim, um degrau mais galgado na escala da civilização. Desejava um processo de fusão que assegurasse a liberdade e progresso dos dois povos peninsulares sem tiranizar Portugal, que deveria começar pelas relações intelectuais, seguida das económicas, com o estabelecimento de um zollverein pleno. A obra parecia-lhe, pois, aconselhável, já que encerrava "o único porvir feliz que resta[va] aos habitantes de Portugal" ([MAS], 1852: XIV).

Pela mesma altura, José Félix Henriques Nogueira, principal precursor do republicanismo português, idealizou uma federação de municípios que seria completada, a nível externo, com a federação dos povos ibéricos. Nos seus Estudos sobre a Reforma em Portugal, também de 1851, recusava a fusão mas defendia a federação peninsular que deveria obedecer à divisão provincial já consagrada pelo tempo e pela tradição, constituída por quinze estados: Portugal e catorze províncias espanholas. Esta fragmentação da Espanha refletia o desejo de destruir a hegemonia política castelhana sobre as restantes regiões com as quais Portugal estabeleceria um contrato político, formando-se uma grande nação peninsular - a Ibéria dos Povos. Aliás, a federação parecia-lhe "altamente necessária" para todos os outros povos europeus que tendiam a

\footnotetext{
${ }^{1}$ As três edições portuguesas que conheceu foram as seguintes: A Ibéria. Memória escrita em língua espanhola por um filo-português, e traduzida em língua portuguesa por um filo-ibérico, Lisboa: Tip. de Castro \& Irmão, 1852 (diversos testemunhos referem que esta publicação se deu em dezembro de 1851); $A$ Ibéria. Memória em que se provam as vantagens políticas económicas e sociais da união das duas monarquias peninsulares em uma só nação. Escrita originalmente em espanhol por um filo-português, e traduzida e precedida de um prólogo por um jornalista português. Segunda edição correta e aumentada pelo autor em janeiro de 1853, Lisboa: Tip. Universal, 1853; A Ibéria. Memoria sobre a conveniência da união pacífica e legal de Portugal e Espanha escrita por Dom Sinibaldo de Mas, ex enviado extraordinário e ministro plenipotenciário de S. M. C. na China. Traduzida em português. Terceira Edição (Corrigida). Lisboa: Tipografia do Progresso, 1855.
} 
"agrupar-se em nacionalidades robustas", pelo que esse seria o caminho que teriam de seguir “os povos italianos, alemães, eslavos e magiares" (SILVA, 1976: 163).

O debate estava, pois, lançado, e, a partir daqui, a polémica instalou-se. A defesa da utopia ibérica assumiu duas fórmulas predominantes: a monárquica unitária, que previa a união peninsular sob uma coroa única, punha a tónica na restauração da importância da Península no concerto das nações e na ideia de prosperidade económica, na promessa do “imenso porvir de grandeza e glória" (CALDEIRA, 1853: 287); e a republicana federalista, que à nostalgia das antigas autonomias locais mesclava a doutrina federativa colhida nos exemplos dos Estados Unidos da América e da Suíça, aliando às vantagens de índole económica as necessárias garantias cívicas.

Apesar da diversidade opinativa quanto à arquitetura da federação peninsular, a via federalista passará a inspirar o pensamento republicano e progressista de Oitocentos, confiante de que a livre associação dos povos encontraria os seus caminhos. Tal otimismo ressaltava das palavras finais do ensaio de Joaquim Maria da Silva, que, em 1854, previa o estabelecimento dos Estados Unidos da Ibéria: "Felizes os que então viverem! Beneméritos da humanidade os que concorrerem com os seus esforços e vontades para o alcance e realização dessa idade de ouro, de paz, de fraternidade". À semelhança de outros pensadores, o utopismo deste açoriano previa patamares superiores de entendimento supranacional, pois considerava que, mais do que a união peninsular, a missão dos povos providencialmente postos à entrada da Europa consistia em começar "a grande reforma do género humano", isto porque à sua união juntar-se-iam os irmãos da antiga América espanhola e portuguesa e, depois, viriam as outras nações, uma a uma, "até que o género humano se funda em uma só família com uma só religião, com uma só língua, com uma só lei” (PEREIRA, 2006: 109).

Assim, o ideal ibérico assumiu-se como um messianismo que não só resolveria os problemas candentes do país, como responderia às aspirações humanitárias e filosóficas dos mais inconformados. Raimundo Capela, um velho colega de Coimbra de Antero de Quental, aquando da morte deste, escreveu na Gazeta de Notícias, do Rio de Janeiro: “A união ou a fusão ibérica parecia-lhe e parecia a todos nós uma conveniência política e uma necessidade fisiológica" (apud PAXÊCO, 1917: 64). Mas esta afirmação espelhava parte da verdade, em vários casos correspondendo apenas a certas fases, geralmente iniciais, do pensamento e da vida dos intelectuais que sobre o assunto se pronunciaram. 


\section{Três percursos diversos: Antero de Quental, Oliveira Martins e Teófilo}

\section{Braga}

Desde logo, Antero de Quental (1842-1891). Entusiasta e veemente no opúsculo publicado dois meses após a revolução de setembro de 1868, que destronara a rainha espanhola, finalizava afirmando que "o único ato possível e lógico de verdadeiro patriotismo consiste em renegar a nacionalidade" (QUENTAL, 1868: 39). Três anos mais tarde, nas Conferências do Casino, ainda rematava as Causas da Decadência dos Povos Peninsulares nos últimos três séculos com o apelo à revolução em nome da paz, e à federação republicana em nome da autonomia municipal. Mas a decepção virá pelos anos 1873-1875, com o fracasso da República espanhola, o abandono, ou destruição mesmo do Programa dos Trabalhos para as Gerações Novas, o agravamento da doença depressiva. Em carta ao editor Wilhelm Storck (1887), o velho socialista relembrou a sua apologia da federação ibérica, ilusão da qual desistira à força de golpes brutais.

Oliveira Martins (1845-1894), por sua vez, foi sempre mais contido nesta matéria e, segundo algumas opiniões, o seu pensamento não foi iberista no sentido estritamente político, mas teve pontos de contato com narrativas iberistas (MATOS, 2006: 361). Entre 1869 e 1872, adepto do princípio federativo como possível síntese entre liberdade e autoridade, acreditou na federação republicana ibérica após a revolução espanhola de $1868^{2}$, mas paulatinamente matizou estas ideias, vindo a recusar o federalismo proudhoniano no opúsculo Eleições (1878). Já na História da Civilização Ibérica (1879) defendeu que a origem dos povos ibéricos resultava da combinação dos berberes do Norte de África (líbio-fenícios) com a influência disciplinadora dos romanos, e realçou a ideia de génio ou alma peninsular, descortinando para a Península movimentos decisivos para o futuro da humanidade, pelo que chegou a propor uma união anfictiónica dos povos europeus. No Portugal Contemporâneo (1881) dedicou um subcapítulo ao estudo do iberismo, considerando que, então, ele persistia no pensamento republicano federalista. Em finais de 1889, num artigo do Tempo, intitulado "Cá e Lá", a propósito dos receios dos espanhóis relativos à instauração da república em Portugal por influência da recentemente implantada no Brasil, admitiu que esse país não exercia "sobre o nosso influência mental", que o republicanismo português, pela sua propensão iberista, não

\footnotetext{
${ }^{2}$ Como demonstra nos cinco artigos sobre o tema "Do princípio federativo e sua aplicação à Península Hispânica", que escreveu em setembro de 1869 no Jornal de Comércio, ou ainda o texto "O golpe militar de 19 de Maio de 1870 e a ditadura militar", publicado no periódico A República.
} 
ganhava "entre nós foros de vontade coletiva" e se opunha à "vontade nacional autonómica", concluindo que "não se quer ser republicano porque não se quer ser ibérico" (MARTINS, 1957: 251-253). Todavia, no mesmo periódico, logo no mês seguinte (25 de janeiro de 1890), em plena ressaca do Ultimato inglês, publicou o texto "Alianças" (MARTINS, 1957: 259-271), no qual afirmou que a Grã-Bretanha "como um vampiro sugou-nos de vários modos", propondo então com a monarquia vizinha, com quem se tinha "identidade de interesses, relações progressivamente mais entranhadas, afinidades de tradições, comunidade de alma e irmandade de história", uma aliança "estável, natural, fecunda e duradoura", em que se robusteceria a nacionalidade e assim se evitaria a sempre temida absorção por Espanha. Essa era a única “aliança possível”, segundo concluía da análise do xadrez internacional de fim de século, em que não afastava um cenário de guerra. Essa aliança distinguia-se "dos protetorados disfarçados, como foram o inglês, transitoriamente o francês ${ }^{3}$, e como seria a aliança com os Estados Unidos", preconizada por alguns, mas que Martins rejeitava, pois com ela o país embarcaria na total dependência de uma potência poderosa e imperialista: "Pela expansão da sua força, principalmente pelo aumento prodigioso da sua produção industrial, a grande república americana ambiciosa pôr um pé na Europa para intervir nas suas questões, para também disputar os seus mercados". Quanto à federação latina - tão propalada pelos republicanos - Oliveira Martins considerava-a "um devaneio romântico", refutada pelo vínculo que a Itália mantinha com a Alemanha, opinando que numa aliança luso-germânica Portugal só poderia pagar a proteção com "algum pedaço de colónia", aliás o mesmo que a Inglaterra pretendia, pelo que não valia a pena trocar, sendo a Rússia “outra fantasia”. Os blocos de forças moviam-se, viviam-se as "vésperas de grandes acontecimentos", isto é, "talvez este fim de século" fosse "profundamente assinalado na existência internacional da Europa"; por isso, sem a aliança espanhola e sob o efeito da humilhação britânica, Martins via Portugal sozinho, isolado, “à espera de uma proteção salvadora da Rússia, dos Estados Unidos, da Alemanha, da China ou do Japão", condenado pela ameaça inglesa ou por "toda esta tempestade que se sente no ar", como "um prólogo de uma conflagração maior ainda".

Nos inícios do século XX, alguns republicanos viriam a renunciar abertamente ao ideal, como Sampaio Bruno (1857-1915), que se penitenciou dos artigos que publicara nos jornais do Porto O Norte Republicano e A Folha Nova. Fez um pungente ato de

\footnotetext{
${ }^{3}$ Nuno Monteiro e António Costa Pinto defendem que o século XIX português foi marcado por dois nacionalismos sucessivos, o antifrancês e o antibritânico (MONTEIRO \& PINTO, 2000: 232-245).
} 
contrição por ter compartilhado da "errada doutrina da federação peninsular como meio de se criar um grande Estado: a Ibéria, a opor à Inglaterra, à França, à Rússia, à China, se calhasse". Apesar de nem ele nem os seus companheiros tivessem querido que por via do federalismo republicano peninsular Portugal se tonasse "uma província de Espanha", vendo-o como o "único modo de uma aproximação livre possível” entre os dois países, percebia agora que tal "não passava duma ilusão" (BRUNO, [1906] 1987: 113-114).

Não obstante a evolução e avatres de pensamento que então e posteriormente se geraram, iberismo e associação internacional - nas suas múltiplas variantes - percorreram decididamente caminhos comuns. O aludido federalismo republicano assentou a sua propaganda em dois aspetos fundamentais. Um consistia na afirmação peremptória do seu anti-iberismo, ao identificá-lo com fusão ou anexação, e reiterar a ideia de que a federação era justamente o oposto, isto é, a salvaguarda das nacionalidades. Por isso, e a título de exemplo, em 1880, na sua História das Ideias Republicanas em Portugal, Teófilo Braga apelaria de "monstruosa conclusão" à renúncia da nacionalidade proposta uma dúzia de anos antes por Quental, e, no ano seguinte, em 10 de abril, o seu discípulo Teixeira Bastos publicaria no jornal Vanguarda um artigo intitulado "Não somos ibéricos" (HOMEM, 2001a e 2001b). A segunda vertente prendia-se com o corolário lógico da sua utopia de pacifismo universal, reforçado pela doutrina positivista que valorizava a cooperação entre os povos; assim, cada vez mais, os seus teóricos defendiam ora os Estados Unidos da Europa ora, pelo menos, a grande federação latina, que contrabalançaria outras federações de raça como o pangermanismo e o pan-eslavismo.

Nesta conformidade, Teófilo Braga (1843-1924) defendeu as bases étnicas da nacionalidade no quadro da lei dos três estados, partindo do conceito romântico de raça no qual via o postulado comtiano da conciliação do Progresso com a Ordem. Assim, criou a (forçada) teoria do moçarabismo para sustentar a individualidade étnica do povo português e defendeu uma federação republicana de base etnológica, inspirado em Henriques Nogueira e na obra do catalão Pi y Margall (designadamente As Nacionalidades, de 1876). Sistema rígido e determinista, sem dúvida, mas que lhe forneceu certezas reconfortantes, face aos desânimos e decepções de Quental e Martins, com quem manteve, aliás, acesas polémicas. No estudo Sistema de Sociologia (1884) condenou a "união ibérica", entendendo esse conceito como exclusivo do unitarismo monárquico, quer português quer espanhol, o qual produzira, ao longo da história, a "morte das liberdades locais e a atrofia de uma raça ativa", com a Inglaterra a aproveitar ardilosamente as hostilidades mútuas. Na sua ótica, Portugal deveria ter centrado os seus 
acordos com a França que, juntamente com a Espanha e a Itália, constituíam os órgãos vitais da civilização ocidental, os Estados mais adiantados para formarem uma federação. Todavia, esta federação latina tinha debilidades, como o próprio reconhecia: a política francesa não se compatibilizava com a ideia de federalismo e os seus republicanos não se desviavam da via unitarista. Curiosamente, foi por influência gaulesa que Teófilo e os seus correligionários optaram por essa mesma solução, uma vez no poder, isto é, após o 5 de Outubro de 1910.

Já próximo do fim do século, em 1894, na obra A Pátria Portuguesa. O Território e a $\operatorname{Raça}^{4}$ retomou as suas teorias de sempre: a fundamentação étnico-mesológica da nacionalidade portuguesa, sem esquecer as tradições e profecias nacionais; a excelência do federalismo; a confederação latina; e o sentimento de Pátria, que, nas palavras de Teófilo, era "necessário revivificar". A questão do patriotismo assumia então particular acuidade, como se verifica no texto preliminar da referida obra que alude ao banquete que reunira formalmente republicanos espanhóis e portugueses, realizado em 24 de junho de 1893, em Badajoz, e que as fações monárquicas exploraram largamente, inclusive no Parlamento, como mais uma conspiração ibérica. Teófilo aproveitou então para transcrever o discurso que enviara, já que não pudera estar presente. Aí evidenciou o equívoco que separava os dois povos, mantendo entre eles uma "aversão implacável” - a união ibérica. Esta apenas interessava às dinastias, enquanto a república era esperança de paz, a paz peninsular que parecia estar sempre por um fio:

Feita a república nos dois países, acabará essa ameaça permanente de invasão espanhola que traz Portugal acorrentado ao jugo espoliador e brutal da Inglaterra; e os dois Povos confederados tornarão a Espanha uma potência europeia, verdadeiro ponto de apoio da confederação latina ou ocidental, em cujos povos ainda hoje existe a parte mais culta, moralizada e consciente.

(...) Diante deste ponto de vista mais avulta a situação irracional em que se acham em frente um do outro Portugal e Espanha, embaraçando-se e depauperando-se. Só poderemos sair dela, reconstituindo-nos pela república, única solução científica e em harmonia com a dignidade individual e com o estado da consciência moderna; enquanto ao passado reconhecendo a

\footnotetext{
${ }^{4}$ Estudo que suscitou de Sílvio Romero uma crítica extensa que deu lugar à obra A Pátria Portuguesa. $O$ Território e a Raça. Apreciação do livro de igual título de Teófilo Braga, publicada em 1905, gerando uma controvérsia analisada no artigo de PAREDES, 2006: 103-119.
} 
autonomia dos Estados ou nações peninsulares, e enquanto à aspiração hodierna federando-as em uma grande potência (BRAGA, 1894: XIII-XIV).

\section{Magalhães Lima - federalismo e pacifismo, federação latina, união ocidental, pan-lusitanismo e confederação luso-brasileira}

Sebastião de Magalhães Lima (1850-1928) partilhou os ideais do seu mestre Teófilo Braga, embora tivesse trilhado um percurso de vida bem diferente. Deixou-se seduzir pelos ideais maçónicos e tornou-se grão-mestre do Grande Oriente Lusitano Unido durante largos anos; foi advogado (por pouco tempo), escritor e jornalista, mas destacouse sobretudo como publicista. Com efeito, participou em numerosos congressos, comícios, banquetes e conferências, vindo a destacar-se na difusão dos ideais federalistas e pacifistas, pelo que empreendeu numerosas viagens ao estrangeiro que a sua fortuna pessoal custeava (GARNEL, 2004: 16). Inscreveu-se como membro ativo da Liga Internacional da Paz e da Liberdade, com sede em Genebra, fundada por Garibaldi, sob a presidência honorífica de Victor Hugo, tornando-se um propagandista reconhecido do pacifismo ao longo da sua vida. Em 1874, ainda estudante em Coimbra, traduziu a obra de Charles Lemonnier, Os Estados Unidos da Europa.

Nascido em 1850, no Rio de Janeiro, cidade que deixou antes de aprender as primeiras letras, não deixou de ser marcado por "radiosas figuras" do republicanismo brasileiro e proeminentes antiescravagistas ${ }^{5}$, que evocou em obra memorialista publicada no ano anterior à sua morte, pois privara com muitos deles na Europa, designadamente em Portugal, Espanha e França (LIMA, [1927] s.d.).

Sem surpresa, o Ultimato britânico foi, também para ele, um marco que incitou à ação na luta contra a submissão do Portugal brigantino à política do Foreign Office. Sob o lema "ou federado com Espanha ou escravos da Inglaterra", realizou uma "peregrinação patriótica" (LIMA, [1927] s.d., I: 145-149) de seis meses pela Europa, cujo relato resultou na publicação da obra Pela Pátria e pela República (1890). Nesta obra revelou o seu credo numa federação latina, já que estes povos se encontravam desprestigiados face aos blocos hegemónicos germânico, eslavo e anglo-saxónico. Daí "o acolhimento dado por Magalhães Lima às ideias veiculadas pela União Mediterrânica", sediada em Paris e

\footnotetext{
${ }^{5}$ Rangel Pestana, Benjamin Constant, Quintino Bocaiuva, Campos Sales, Lopes Trovão, José do Patrocínio, Saldanha Marinho, Assis Brasil, Rui Barbosa, Joaquim Nabuco, entre vários outros.
} 
fundada por Marc-Amédée Gromier, que visava a realização de um zollverein mediterrânico, no sentido de um espaço económico uniformizado, que chegava à abolição das alfândegas entre os países constituintes, como forma de fazer frente à Alemanha unificada e ao "crescente reforço do imperialismo britânico" (GARNEL, 2004: 61-62). Latino Coelho, que prefaciou também esta obra (à semelhança de várias outras, de simpatias iberistas, escritas por nacionais e estrangeiros) destacava que o seu amigo advogava as ideias de paz perpétua e universal ao colocar como necessidade imperiosa a instituição da "federação republicana dos povos latinos, como preâmbulo à confederação geral da Europa civilizada", sendo essa a base da realização do sonho dos filósofos - "a fraternidade humana" (LIMA, [1927] s.d., I: 148). Nesta obra de doze capítulos, Magalhães Lima não deixou de tratar num deles “O Brasil” (LIMA, [1927] s.d., I: 173185), embora de forma indireta, abordando as comemorações em Paris do primeiro aniversário da República brasileira e, em 18 de novembro do ano anterior, um banquete em honra de Garibaldi, em que Lima fora um dos oradores, tendo, segundo transcrição do discurso, unido o seu brinde ao Brasil ao tributo a Garibaldi - "o herói de dois mundos" - e a sua luta de dez anos nesse país. À semelhança de largas partes do livro, são sobretudo as sociabilidades republicanas que emergem, neste caso a francesa, a brasileira e a portuguesa, se bem que a última quase exclusivamente protagonizada pelo autor do livro, que na fórmula federativa do Brasil antecipava o sucesso da federação peninsular: "Os que veem um perigo numa federação entre Portugal e Espanha, basta que atentem um pouco na constituição dos Estados Unidos do Brasil, para que tais receios se desvaneçam" (LIMA, [1927] s.d., I: 185).

O seu entusiasmo sobre o projeto de confederação latina levou-o a acrisolar a defesa da federação ibérica de base municipalista, de que a obra La Fédération Ibérique (1893) fez eco, no seguimento do atrás referido encontro de Badajoz, do qual foi um dos promotores, dadas as boas relações que mantinha com os republicanos do país vizinho. Nesse resumo das intervenções da reunião luso-espanhola, Magalhães Lima patenteou a necessidade de se alargar a federação à América do Sul e a África. No que toca a este último continente, a preocupação quanto à manutenção dos territórios ultramarinos era evidente, pese embora acreditasse - numa atitude francamente vanguardista - no princípio da autodeterminação e num futuro pacto federativo. Mas o plasma confederal ibero-americano era determinante neste cenário, particularmente o Brasil, após a república (1889), e Magalhães Lima proporcionou um espaço para essa solidariedade luso-brasileira de timbre republicano no prestigiado jornal que fundara no início da 
década de oitenta - O Século. Todavia, reconheceu que o grande responsável por tal ligação foi Latino Coelho, que em Lisboa se tornara o "embaixador" do novo regime brasileiro, fazendo do renomado diário $O$ Século o porta-voz do seu governo provisório, pois Quintino Bocaiuva e Ruy Barbosa enviavam-lhe, quase diariamente, extensos telegramas que contrariavam as notícias que visavam desprestigiar o novel regime. Cerca de três décadas volvidas, o grande publicista recordou o papel do correligionário, falecido em 1891, nestes termos: "Latino, com a sua universal e incontestável autoridade, tornou O Século o órgão da sonhada Confederação luso-brasileira, e previra, com a sua sagacidade, a Confederação ibero-americana, defendida por altas mentalidades, e que se impõe como uma obra de equilíbrio mundial" (LIMA, [1927] s.d., I: 118).

Todavia, em plena guerra mundial, Magalhães Lima reajustou o seu pensamento: em vez da liga latina, passou a advogar a "união ocidental”, isto é, uma federação anglolatina, que contemplava a novidade do alargamento à Inglaterra - já não a opressora do ominoso ultimato de 1890, mas a principal aliada da Tríplice Entente -, cuja cultura se filiava em Roma, mãe comum, que triunfara "sobre a sua eterna inimiga, a barbárie germânica" (LIMA, [1927] s.d., II: 22).

Esta união anglo-latina centrada no Atlântico não deixava de se adequar também à ideia de aliança luso-brasileira, lançada em inícios do século XX por Sílvio Romero e reavivada entre 1917 e 1923 por alguns intelectuais brasileiros e portugueses, destacandose entre estes o médico alienista Bettencourt Rodrigues (1854-1933), exilado voluntariamente no Brasil entre 1892 e 1913 devido às suas convicções republicanas ${ }^{6}$. Com a conferência "O elemento português no Brasil", proferida no Real Gabinete de Leitura do Rio de Janeiro em maio de $1902^{7}$, Romero preconizava o fortalecimento das relações entre os dois países por via de políticas públicas comuns (comerciais, militares, culturais, migratórias, etc.), percepcionando

a construção de ideologias transnacionais em confronto, numa época de constantes ameaças guerristas, referindo o pangermanismo ou o pan-

\footnotetext{
6 Além de Bettencourt Rodrigues e Magalhães Lima, entre outras personalidades, participaram neste projeto, que assumiu diversas tonalidades na sua configuração teórica - "acordo, aliança, liga, união, confederação” -, os portugueses João de Barros, Henrique Lopes de Mendonça, Jaime de Magalhães Lima, Ricardo Severo (também radicado no Brasil desde 1908 e diretor da revista Portvgália), Alberto de Oliveira ou Anselmo Braamcamp Freire, e os intelectuais brasileiros Medeiros e Albuquerque, Graça Aranha, Pinto da Rocha, Spencer Vampré, Domício da Gama, Cavalcanti Melo, Alberto Seabra ou Noé de Azevedo (LEAL, s.d.: 1).

${ }^{7} \mathrm{O}$ contexto histórico desta conferência relacionava-se com a criação da União Ibero-Americana em 1900, no México, durante um congresso pan-americano das Repúblicas hispano-americanas.
} 
eslavismo, e advertia que o desenvolvimento de um possível panamericanismo, para ser eficaz, não podia deixar de ter três expressões independentes: as anglo-americanas, as luso-brasileiras e as hispanoamericanas (LEAL, s.d.: 2).

A ideia encontrou repercussão e veículos de divulgação em Portugal, designadamente através de Coelho de Carvalho, presidente da Academia de Ciências de Lisboa, e Consiglieri Pedroso (vice-presidente e depois presidente da Sociedade de Geografia de Lisboa), desfrutou do ambiente propício subsequente ao 5 de Outubro de 1910, e, já durante o primeiro conflito mundial, Bettencourt Rodrigues expôs o seu modelo confederal em entrevistas publicadas no jornal monárquico $O$ Dia e no mensário Atlântida, dirigida pelo republicano João de $\operatorname{Barros}^{8}$.

Em carta dirigida nesse ano de 1917 a Bettencourt Rodrigues, apoiando a sua iniciativa, Magalhães Lima admitiu que os anos da guerra lhe haviam trazido "a convicção de que a solução para o problema do futuro há de residir na forma federativa". Nesta conformidade, o "Atlântico será o continuador do Mediterrâneo", isto é, "Mare nostrum chamaremos nós, brasileiros e portugueses, ao Atlântico". Sublinhava ainda que as vantagens para ambas as partes nesse empreendimento eram enormes e a sua realização poderia começar por "um plebiscito, aberto na imprensa dos dois países", com o fito de tornar "a questão palpitante, de uma flagrante atualidade". Mais: antecipava então que uma confederação luso-brasileira seria um fator positivo e seguro "para fortalecer a Sociedade das Nações que resultará da Entente dos povos aliados". Considerava que os continentes fraternizavam - "A Europa é a América, e a América é a Europa" - e partilhava de um conceito então em moda, o "pan-lusitanismo" - defendido por monárquicos e republicanos, como Alberto Oliveira, Ricardo Severo, Henrique Lopes de Mendonça, entre outros -, afirmando: “A nova e grande Lusitânia não só é possível, senão também se transmutará numa luminosa realidade imposta pelas circunstâncias da nova era que a guerra nos vai trazer" (LIMA, [1927] s.d., II: 26). Esta afirmação era praticamente uma resposta à pergunta que consubstanciava o título da entrevista de Bettencourt a João de Barros - "Uma ideia a defender. A Confederação Luso-Brasileira. Será possível uma nova e grande Lusitânia?" - publicada na Atlântida em 15 de junho de 1917, assim como o foi também esta carta de Lima, dois meses depois, em 15 de agosto.

\footnotetext{
${ }^{8}$ A sua obra Uma confederação luso-brasileira seria publicada em 1923, numa fase de agonia da Primeira República portuguesa e também do próprio projeto de aproximação entre os dois países.
} 
Indo um pouco mais além dos clichés da apologia do princípio confederativo e pacifista, na obra de 1918, L'Effort Portugais et L'Union Occidental, Magalhães Lima expôs os contornos do processo, colocando a tónica nos esforços de guerra português, francês e inglês, bem como na formação sucessiva da federação ibérica e das uniões latina e ocidental. O Brasil, pátria irmã, surgia, sem surpresas, numa retórica afetiva:

Quand, après la déclaration de guerre de l'Allemagne au Portugal, les nouvelles me sont parvenues des vibrantes manifestations qui avaient eu lieu à Rio de Janeiro, avec quelle joie il m'a été donné de constater que c'était le sang de mon sang, l'esprit de mon esprit qui se traduisaient dans un geste d'inoubliable noblesse, d'inoubliable solidarité. C'était la communauté hautement

avouée de deux peuples qui, par leurs profondes affinités ethniques, leur histoire, leur langue, ne font qu'une même patrie spirituelle. A partir de ce moment, le Brésil était devenu pour nous, Portugais, un belligérant, un membre de l'Entente, dans la plénitude de son cœur, en attendant de l'être dans la plénitude de ses forces. S'il n'entrait pas dès lors en guerre, il déclarait, du haut de la tribune, par la voix de ses plus illustres représentants, sa ferme résolution d'accompagner les Alliés partout, dans la mauvaise comme dans la bonne fortune. Les Lusiades vont être écrites de nouveau par les deux peuples identifiés dans la même gloire. Le Brésil reste toujours l'immortalité du Portugal (LIMA, 1918: 37).

A confederação luso-brasileira, por sua vez, era colocada como consequência do conflito mundial, no contexto da união ocidental, que pressupunha a formação de uma frente mediterrânico-atlantista, que incluiria, em seguida, os Estados Unidos da América:

Si une alliance offensive et défensive n'est pas encore conclue, il ne serait pas pour étonner que la guerre provoquât une confédération entre les deux nations. C'est le désir d'une association intime avec le Brésil qui, joint aux raisons de notre alliance anglaise et aux nécessités de notre avenir africain, a fait naître au Portugal l'idée de la constitution immédiate d'une union perpétuelle entre tous les peuples riverains de l'Atlantique, l'idée de "l'union occidentale". Cette confédération luso-brésilienne - dont mon illustre ami Bettencourt-Rodriguez a rédigé un projet, - reposerait, en effet, sur les fondements 
suivants:

$1^{\circ}$ La nécessité de l'union latine justifiée non seulement comme une mesure matérielle de défense commune des groupements qui la composent, mais aussi comme un besoin moral d'opposer à la barbarie germanique l'humaine et traditionnelle civilisation partie des bords médterranéens;

$2^{\circ} \quad$ L'affirmation de l'union latine comme un premier pas vers l'union anglo-latine;

$3^{\circ}$ L'étroite alliance politique, intellectuelle et économique que les conditions de guerre ont rendu indispensable entre les peuples de race anglo-saxonne, Angleterre et Etats-Unis, et les peuples de race latine d'Europe et d'Amérique. L'union latine, qui nous garantirait la possession de la Méditerranée, aurait pour complément l'union anglo-latine, qui nous garantirait la possession de l’Atlantique (LIMA, 1918: 38-39).

E o papel de Portugal era determinante nesse passo que ligava os dois lados do Atlântico, qual primeira pedra do grande edifício:

Par ce premier traité luso-brésilien, le Portugal jouerait le rôle d'initiateur de l'union anglo-latine ou union occidentale.

Ce rôle, qui peut paraître bien grand pour notre petit pays, si on ne considère que l'étendue de son territoire européen, n'est pas trop grand, si on veut bien considérer la constance de l'esprit portugais aspirant, aujourd'hui comme autrefois, à faire de sa coopération à l'action mondiale l'idéal de son sentiment national.

Par notre initiative d'autrefois, nous avons rendu de grands services au monde, nous pouvons lui en rendre d'aussi grands, par notre initiative d'aujourd'hui, en faisant triompher cette idée dont nous nous sommes faits les propagateurs, l'idée d'union occidentale, le plus sûr moyen - je vais le démontrer - pour finir promptement la guerre et organiser logiquement la paix, ces deux choses dont dépend l'avenir de l'humanité tout entière! (LIMA, 1918: 39). 


\section{Hipólito Raposo e António Sardinha - o Integralismo Lusitano face ao Iberismo e ao Hispano-americanismo}

O pensamento dos integralistas, com destaque para António Sardinha (1887-1925), viria a produzir contributos fundamentais para o tema em análise, com similitudes com as dos federalistas, aliás curiosas, dada a diversidade do campo ideológico, mas também com clivagens de monta. Hipólito Raposo (1889-1953), por exemplo, deixou bem clara a sua aversão ao pensamento de Magalhães Lima, a quem minimizou a influência sobre os correligionários, tendo sublinhado o radicalismo das suas ideias assente nas vertentes iberista e maçónica: "É justo reconhecer que muitos dos republicanos de categoria nunca foram iberistas, nem quiseram perfilhar as conclusões do célebre livro de Magalhães Lima - La Fédération Ibérique, verdadeira bíblia do Maçonismo Político Peninsular" (RAPOSO, 1945: 23). Raposo era um dos elementos do grupo do Integralismo Lusitano que, em 1915, organizou as Conferências da Liga Naval, cujas atas foram dadas à estampa no ano seguinte, com o título A União Ibérica. A introdução da obra esclarecia as razões do novo sobressalto: a escalada da propaganda fusionista em Espanha, na imprensa periódica, nos textos do político Juan Nido y Segalerva e do professor de Valladolid Vicente Gay, bem como nos discursos, e mesmo atos, de Afonso XIII, sempre tão comentados em Portugal ${ }^{9}$. Apesar da predominância dos estímulos externos, os integralistas monárquicos não tinham dúvidas quanto às responsabilidades do novo regime: "Os desvarios da República de Portugal alentam de novo a questão ibérica" ${ }^{10}$. Na ótica deste grupo, a ideia de união ou federação peninsular, radicava no "humanitarismo revolucionário e romântico", no "delírio democrático" que sonhava com os "conceitos retrógrados" de fraternidade universal, abolição das pátrias ou grande FamíliaHumanidade, como se isso fosse o bastante "para garantir a paz, gerar a abundância, a virtude", oferecer "um eldorado de encanto em permanente festim" (LIGA NAVAL, 1916: s.p.).

A intenção dos integralistas em 1915-1916 era simples, demonstrar que "Portugal tem tanta individualidade como Castela" (LIGA NAVAL, 1916: s.p.). A esse propósito se subordinava o texto inaugural - "O Território e a Raça" - de Sardinha, que apresentava óbvias semelhanças com o título do seu antípoda político Teófilo Braga, de quem aceitava

\footnotetext{
${ }^{9}$ Sobre os "perigos espanhóis" nos inícios da República veja-se BRANDÃO, [1933], 2000: 49-53.

${ }^{10}$ Frase inaugural da obra de compilação das conferências da Liga Naval, A Questão Ibérica.
} 
a tese da origem étnica da nacionalidade e da importância aglutinadora do municipalismo, recusando, obviamente, a conclusão da federação ibérica republicana. Ao apresentar o perigo ibérico como tema central, defendia que a pátria devia reabilitar-se pela Ordem: "Só vivem os povos que sabem viver". Seguindo o credo integrista, exautorava as doutrinas liberais e a maçonaria ("servidora desvelada da fusão ibérica") como a origem de todos os erros modernos, crente que os nossos desvarios só poderiam escancarar as portas aos espanhóis, denunciando a traição do "estrangeiro do interior" ". Ao atribuir à pátria uma realidade fisiológica - um corpo humano e uma alma que é o génio da raça (ou razão afetiva do povo) - ficava patente a sua concepção determinista orgânica. Curiosamente, baseava-se na obra do geógrafo anarquista Elisée Reclus (Nouvelle Géographie Universelle) e na do positivista José Augusto Coelho (1909), que, a seu ver, apenas enfermava do "preconceito democrático"12, para explicar que era precisamente a geografia e a antropologia - o meio e a população, o território e a raça - que tornavam Portugal uma realidade inconfundível, ao mesmo tempo que perseverava na diferenciação psicológica dos povos: os espanhóis guerreiros, saqueadores e místicos; os portugueses afetivos, missionários e líricos. A Sardinha se voltará mais à frente, pois o seu pensamento sofrerá alterações substanciais, durante o exílio que viveu em Espanha, entre 1919 e 1921.

Hipólito Raposo forneceu, anos mais tarde, uma interpretação distinta dos acontecimentos que levaram à germinação, mas também fenecimento, da ideia da confederação luso-brasileira. Também ele ${ }^{13}$ foi convidado por Bettencourt Rodrigues e Coelho Carvalho para uma conversa em casa do primeiro, já que estes "dois ilustres republicanos" pretendiam "de algum modo exautorar o iberismo dos seus correligionários" e fortalecer, "sem perigo, a posição internacional do país em guerra". O seu objetivo era

\footnotetext{
${ }^{11} \mathrm{O}$ rol de intelectuais e políticos portugueses que culpabilizava é extenso: Gomes Freire, Fernandes Tomás, Mouzinho da Silveira, Alexandre Herculano, Oliveira Martins, Magalhães Lima, entre outros, afirmando ainda: "Se um dia se quiser informar o processo do Constitucionalismo em Portugal, não carecemos de outra fonte de instrução. A questão ibérica é bastante" (LIGA NAVAL, 1916: 26). Idêntica condenação do século XIX e, consequentemente, do iberismo e dos seus presumíveis responsáveis, faria mais tarde Hipólito Raposo na obra Aula Régia, 1936.

${ }^{12}$ Como Sardinha dizia, era seu objetivo estudar as sociedades ibéricas "numa grande síntese sistemática e à luz da ciência moderna" para, após esta larga exposição, chegar à conclusão de que "o iberismo é um absurdo e que Portugal é uma nacionalidade com característicos nítidos e irredutíveis, de verdadeira e real independência".

13 A participação dos monárquicos integralistas e, em particular, de Hipólito Raposo, não é apontada no artigo citado de Castro Leal, certamente pela sua fraca expressão na matéria, como a seguir se explica.
} 
chamar a atenção dos Portugueses, por cima das divergências do regime, para a realidade do Brasil, estabelecendo com o país irmão um sistema de relações externas de alta conveniência histórica, intelectual, política e económica, cujas vantagens se viriam a efetivar depois da guerra.

O pensamento do Dr. Bettencourt Rodrigues concretizava-se numa íntima aliança, quase confederação de Portugal e Brasil, com reciprocidade de direitos de cidadania, menos os de natureza política, validade de cursos e exercício de profissões, permuta de professores, enfim, um largo plano de interpenetração que me levava a visionar a ressurreição do Reino Unido de Portugal e Brasil, sob o cetro de El-Rei D. João VI... (RAPOSO, 1945: 27)

Efetivamente, cada um vê o que quer ver, e Hipólito Raposo acreditava que do Brasil "não poderiam vir-nos maus intentos nem ocultos desejos de absorver ou matar a sua antiga Mãe-Pátria”, mas tinha francas reservas quanto à exequibilidade de um projeto em que a maioria das vantagens pendiam para o lado português e por ignorar o "verdadeiro estado de espírito do Brasil" relativamente a Portugal. Todavia, se fossem alcançados todos os desideratos sonhados, afigurava-se-lhe "útil todo o propósito da nossa aproximação com o Brasil, tantas vezes tentada em seguras bases e outras tantas malograda por fúteis pretextos ou pela reação de interesses ameaçados" (RAPOSO, 1945: 28). Assim, e "como se tratava de um movimento nacional, sem distinção de credos políticos", Raposo fora o escolhido para através dele se granjear o apoio do Integralismo Lusitano e, por sugestão de Coelho de Carvalho, ficou encarregado de escrever um projeto de manifesto do seu "grupo patriótico", que, aliás, o aprovou "sem qualquer emenda", e cujo original foi deixado nas mãos de Bettencourt (RAPOSO, 1945: 28). Esse texto, datado de 20 de junho, que Raposo considerou "prudente e brando", sem jamais usar o conceito de "confederação", dedicava as primeiras palavras ao Brasil e seu povo, para quem deviam ir então e sempre os "melhores intuitos de ligar as duas pátrias de mesma origem por tão íntimos sentimentos, interesses e destinos". O restante texto aludia ao "perigo ibérico" que se tornara uma "conspiração permanente", com sucessivos "propósitos de absorção" e os "impulsos federativos" a "servir os interesses de Castela". O parágrafo final resumia essa posição que não dissociava a relação de Portugal com o Brasil da sua relação com Espanha:

Dominados pela convicção ardente que determina a nossa atitude, acima de opiniões pessoais sobre formas de governo e em nome da nossa consciência 
de Portugueses, declaramos julgar neste momento inoportunos e até perigosos todos os projetos de harmonia, federação ou aliança ibérica, afirmando ainda e sempre que o mais alto interesse nacional impõe a sólida união de Portugal e Brasil, respeitada a individualidade política que o destino assinar a cada uma das Nações Irmãs (RAPOSO, 1945: 30).

Para este integralista, foram dois os acontecimentos políticos da vida interna portuguesa que adiaram os planos - os "embaraços e perturbações da mobilização de tropas portuguesas para a guerra" e "a malfadada revolução de Machado dos Santos" -, pelo que se extinguiu "mais uma vez o fogo-fátuo da aproximação com o Brasil que praza a Deus venha um dia a estabelecer-se com bases seguras e duradouras, para maior bem da Comunidade Portuguesa e do grande Império da América Hispânica" (RAPOSO, 1945: 31).

Como se referiu, durante o exílio, Sardinha descobriu a "Espanha-Madre”. Escreveu então vários textos em revistas e jornais que viriam a ser compilados num livro póstumo, À Lareira de Castela (1943), que pretendiam retificar o seu "nacionalismo alarmado" de 1915 e denunciar a "lenda negra" de cativeiro e opressão castelhanos que o ultrarromantismo havia forjado. Mais ainda, Sardinha passou a crer na aproximação espiritual dos dois países peninsulares pela defesa dos conceitos de pan-hispanismo e de hispano-americanismo, já que o destino de Portugal e de Espanha encontrava na América o seu prolongamento natural. Tais ideias seriam desenvolvidas em A Aliança Peninsular $^{14}$, obra maior do ideal hispanista que preconizou, publicada um mês antes da sua morte. Aí recuperou as teses de aliança com Espanha de Oliveira Martins (bem como o seu conceito de "génio peninsular") e de Moniz Barreto, formuladas no pós-ultimato, explorando a metáfora deste último: retalhada e dividida a Península jamais deixaria de ser o lenço de Verónica, "a estampa ensanguentada do nosso lento e irremediável suicídio"; vituperou o espectro do iberismo, que considerava um "poderoso dissolvente" das relações luso-espanholas; explicou a diferença psicológica dos povos peninsulares pelos conceitos de "sebastianismo" e "quixotismo" - dois ethos que individualizavam mas não separavam. Assim, História e a Geografia distinguiam, mas simultaneamente ampliavam e completavam, formando uma espécie de "supernacionalismo" ou soma de duas gloriosas pátrias constituindo a "Cabeça da Europa", que, juntamente com a Hispano-América, face à ameaça germânica e eslava, teriam a missão histórica de salvar

\footnotetext{
14 Teve duas edições portuguesas (1924 e 1930) e duas espanholas (1930 e 1939).
} 
a civilização ocidental, entre outros valores por via do catolicismo. A par do seu hispanoamericanismo, evidenciava a recusa do latinismo pela expressa exclusão da França, país gerador que desencadeara a tremenda revolução e seu cortejo de consequências funestas, e de quem os peninsulares sempre haviam sido vítimas, não existindo entre os povos qualquer semelhança moral. Rejeitava inclusive a denominação América Latina, indevidamente utilizada para designar a América Hispânica ou Hispano-América. Em suma, ao iberismo maçónico e ao europeísmo protestante contrapunha o peninsularismo e o hispanismo. Certo é que este intelectual conservador nunca chegou a concretizar as formas que esta aliança poderia assumir, os domínios concretos em que se poderia materializar. Quanto ao Brasil, ironizava sobre a propalada ideia da confederação de Portugal com esse país, se bem que em nota se preocupou em esclarecer que não aludia ao projeto português, que aliás elogiou nestes termos: "Escrita esta página antes do aparecimento do notável livro do doutor Bettencourt Rodrigues, claro que não nos referimos a tão elevada manifestação de patriotismo" (SARDINHA, 1930: 450). Pretendia, sim, expor a falácia em que caíam os que pensavam que Portugal seria a "eterna metrópole" e o Brasil a "colónia perpétua", especificando:

O que pode e há de aproximar o Brasil de Portugal é o que pode e há de aproximar a Espanha das nacionalidades hispano-americanas: a guarda e o prestígio dum tipo de civilização que a todos os hispanos igualmente pertence e que, sendo a base fundamental da sua razão de ser como pátrias livres é, simultaneamente, como simples "programa de conservação" [...], a afirmação dum natural e irresistível supernacionalismo (SARDINHA, 1930: 451).

No tocante ao "supernacionalismo" peninsular, avança apenas, mais uma vez inspirado em Oliveira Martins, com a formação de uma "espécie de liga ou anfictionia" na qual Portugal e a Espanha recobrariam "a preponderância que em direito lhes cabe”, enquanto na América, “as pátrias que da Península derivavam”, depois de sanados os seus problemas internos, "não demorarão a atingir o esplendor e a supremacia para que Deus as convocou" (SARDINHA, 1930: 451-452).

Desta forma, em termos vagos, a Hispano-América, a grande mãe Hispânia, uniase pelo Atlântico que, pelo navalismo, se tornava o Mare Nostrum, conceito que dá título ao último capítulo de A Aliança Peninsular. Neste contexto não surpreende o seu brado: “Acima hispanos de ambas as margens do Atlântico" (SARDINHA, 1930: 454). 
O apelo é inequívoco mas, como já vimos, não é original, pese embora as óbvias diferenças ideológicas.

Assim, o teórico integralista combatia o unitarismo e federalismo ibéricos pela ligação das direitas de Portugal e de Espanha, país onde, aliás, encontrava correligionários à altura: Angel Ganivet, Ramiro de Maetzu, Vasquez Mella ${ }^{15}$. O pan-hispanismo assumia a fórmula da amizade peninsular consubstanciada na "Festa da Raça", que se passou a comemorar a 12 de outubro. Nesse dia de 1924, realizou-se um banquete, curiosamente também em Badajoz, onde Sardinha discursou. Tal como as solidariedades republicanas, também as redes tradicionalistas funcionaram na Península, e em moldes operativos bem semelhantes.

\section{Conclusão}

Iberismo, federalismo ibérico, pan-latinismo, pan-lusitanismo, união ocidental, hispanismo, aliança peninsular, peninsularismo, confederação luso-brasileira, hispanoamericanismo foram doutrinas postuladas entre meados de Oitocentos e o período de entre guerras por intelectuais portugueses de diversos quadrantes ideológicos para pensar a relação entre Portugal e Espanha e a da Península Ibérica e da Europa com a América Hispânica. Parece claro que a profícua e multifacetada doutrinação iberista, assim como as reações que suscitou, propiciaram a enunciação teórica de entendimentos supranacionais estendidos à Ibero-América, as quais variaram consoante os contextos histórico-epocais, bem como em função da ideologia e momento da vida dos pensadores em causa. Estas formulações assumiram, pois, conotações tanto utópicas, quanto distópicas (PEREIRA, 2010).

Um dos tempos-fortes evidenciado neste estudo remete para o período compreendido entre o final do século XIX e a conjuntura que se seguiu ao primeiro conflito mundial, dada a intensa necessidade de alinhamento de blocos geoestratégicos e aproximação de nações com afinidades de tipo diverso, tendo convocado especiais alargamentos à Ibero-América de teorizações cujo cerne radicava em princípios de relacionamento entre os países ibéricos, ou outros, designadamente da Europa ocidental,

\footnotetext{
${ }^{15}$ Figuras que elogiou nos textos que constituem a obra À Lareira de Castela (aliás, a par de Charles Maurras, o único teórico francês cujas doutrinas admirava, abrindo com ele uma exceção que lhe permitiu falar de "hispanismo e latinidade"). Ramiro de Maetzu escreverá o prólogo para La Alianza Peninsular (1930).
} 
oriundas de pensadores que militavam quer no campo republicano, quer no integralismo monárquico, como demonstram os casos analisados, em que se manifestaram similitudes e divergências fundamentais.

\section{Fontes}

BARRETO, Moniz (1891). A situação geral da Europa e a política exterior de Portugal. Revista de Portugal. Lisboa, n. 19, pp. 81-104, dez.

BRAGA, Teófilo (1880). História das ideias republicanas em Portugal. Lisboa: Nova Livraria Internacional.

(1884). Sistema de Sociologia. Lisboa: Tip. Castro Irmão. (1894). A Pátria Portuguesa. O Território e a raça. Porto: Livraria Internacional de Ernesto Chardron.

BRANDÃO, Raul ([1933] 2000). Vale de Josafat. Lisboa: Relógio d'Água.

BRUNO, Sampaio ([1906] 1987). Os modernos publicistas portugueses. Porto: Livraria Chardron de Lello \& Irmão Editores.

CALDEIRA, Carlos José (1853). Apontamentos duma viagem de Lisboa à China. Lisboa: Tip. de Castro \& Irmão, 1853, vol. 2.

COELHO, José Augusto (1909). Evolução geral das sociedades ibéricas. Lisboa: Livraria Moderna, 2 volumes.

LIGA NAVAL (1916). A questão ibérica. Lisboa: Almeida, Miranda \& Sousa Ltd.

LIMA, Magalhães ([1927] s.d.). Episódios da minha vida. Lisboa: Perspectivas \& Realidades, 2 volumes.

([1890]). Pela pátria e pela pepública. Porto: Casa Editora Alcino Aranha \& C. ${ }^{\text {. }}$ (1918). L'effort Portugais et l'union occidental. Auxerre: Imprimerie Gallot.

MARTINS, Oliveira (1879). História da civilização ibérica. Lisboa: Bertrand. ([1881] 1986). Portugal contemporâneo. Lisboa: Guimarães Editores, vol. 1. (1957). Política e história. Lisboa: Guimarães \& C. ${ }^{\text {a }}$ Editores, vol. II, p. 261-271.

[MAS, Sinibaldo de] (1852). A Ibéria. Memória escrita em língua espanhola por um filoportuguês, e traduzida em língua portuguesa por um filo-ibérico, Lisboa: Tip. de Castro \& Irmão.

NIDO Y SEGALERVA, Juan del (1914). La Unión Ibérica. Estudio crítico, histórico de este problema formado con cuanto acerca de él han escrito los historiadores, así portugueses como españoles, y los defensores de ella. Madrid: Tipografías de Prudencio P. de Velasco.

PAXÊCO, Fran (1917). A Escola de Coimbra e a dissolução do Romantismo. Lisboa: Casa Ventura Abrantes, Livraria Editor.

PEREIRA, Maria da Conceição Meireles (edição de texto, introdução e notas) (2006). Felizes os que então viverem! Estados Unidos da Ibéria - uma eucronia federativa de Joaquim Maria da Silva. Vila Nova de Famalicão: Edições Quasi /FLUP.

QUENTAL, Antero de (1868). Portugal perante a revolução de Espanha. Considerações sobre o futuro da política portuguesa no ponto de vista da democracia ibérica. Lisboa: Tipografia Portuguesa.

(1871). Causas da decadência dos povos peninsulares nos últimos três séculos. Porto: Tip. Comercial, 1871.

RAPOSO, Hipólito (1936). Aula Régia. Porto: Livraria Civilização. (1945). Folhas do meu Cadastro. Porto: Edições Gama. 
RODRIGUES, Bettencourt (1923). Uma confederação luso-brasileira: factos, opiniões e alvitres. Lisboa: Livraria Clássica Editora.

ROMERO, Sílvio (1905). A Pátria portuguesa. O território e a raça. Apreciação do livro de igual título de Teófilo Braga. Lisboa: Livraria Clássica Editora de A. M. Redixeira \& C. ${ }^{\text {. }}$.

SARDINHA, António (1930). A aliança peninsular. Porto: Livraria Civilização. (1943). À lareira de Castela. Lisboa: Edições Gama.

SILVA, António Carlos Leal da (org.) (1976). José Félix Henrique Nogueira 1823-1858 - Obra Completa. Lisboa: Imprensa Nacional-Casa da Moeda, tomo 1.

\section{Referências Bibliográficas}

CATROGA, Fernando (1985). Nacionalismo e Ecumenismo. A Questão Ibérica na Segunda Metade do Século XIX. Cultura. História e Filosofia. Centro de História da Cultura da Universidade Nova de Lisboa, vol. IV, pp. 419-463.

GARNEL, Maria Rita Lino (2004). A República de Sebastião de Magalhães Lima. Lisboa: Livros Horizonte.

HOMEM, Amadeu Carvalho (2001a). O tema do iberismo no republicanismo federalista português (1870-1910)". In: LEAL, Ernesto Castro (coord.). O Federalismo Europeu. História, Política e Utopia. Lisboa: Edições Colibri, 2001, pp. 81-88.

HOMEM, Amadeu Carvalho (2001b). O anti-iberismo dos republicanos radicais portugueses (1870-1910). In: HOMEM, Amadeu Carvalho. Da Monarquia à República. Viseu: Palimage Editores, pp. 87-94.

LEAL, Ernesto Castro (s.d.). A Ideia de Confederação Luso-brasileira nas Primeiras Décadas do Século XX. Universidade de Juiz de Fora, Centro de Pesquisas Estratégicas Paulino Soares de Sousa. Disponível em: <http://www.ecsbdefesa.com.br/defesa/fts/LB.pdf>. Acesso em: 22 ago. 2017.

MATOS, Sérgio Campos (2006). Iberismo e Identidade Nacional (1851-1910). Clio, Revista do Centro de História da Universidade de Lisboa. Nova Série, vol. 14-15, pp. 349-400.

MONTEIRO, Nuno \& PINTO, António Costa (2000). Mitos Culturais e Identidade Nacional Portuguesa. In: PINTO, António Costa (coord.). Portugal Contemporâneo. Madrid: Ediciones Sequitur, pp. 232-245.

PAREDES, Marçal de Menezes (2006). A Querela dos Originais: notas sobre a polêmica entre Sílvio Romero e Teófilo Braga. Estudos Ibero-Americanos. PUCRS, Edição especial, n. 2, pp. 103-119.

PEREIRA, Maria da Conceição Meireles (2001). Sinibaldo de Mas: el diplomático español partidario del iberismo". Anuario de Derecho Internacional. Pamplona: Servicios de Publicaciones de la Universidad de Navarra, XVII, pp. 351-370. (2010). Iberismo e Nacionalismo em Portugal da Regeneração à República. Revista de História das Ideias. Faculdade de Letras da Universidade de Coimbra: Instituto de História e Teoria das Ideias, n. 31, pp. 257-284.

MOLINER PRADA, Antonio (1989). La Federación Ibérica y la Revolución de 1848. Ler História. Lisboa, n. 16, pp. 117-136.

RIVAS, Pierre (1982). Utopie Ibérique et Idéologie d'un Fédéralisme Social Pan-Latin. In: Actes du Colloque Utopie et Socialisme au Portugal au XIXe Siècle. Paris: Fondation Calouste Gulbenkian, Centre Culturel Portugais, 1982, pp. 319-330. 